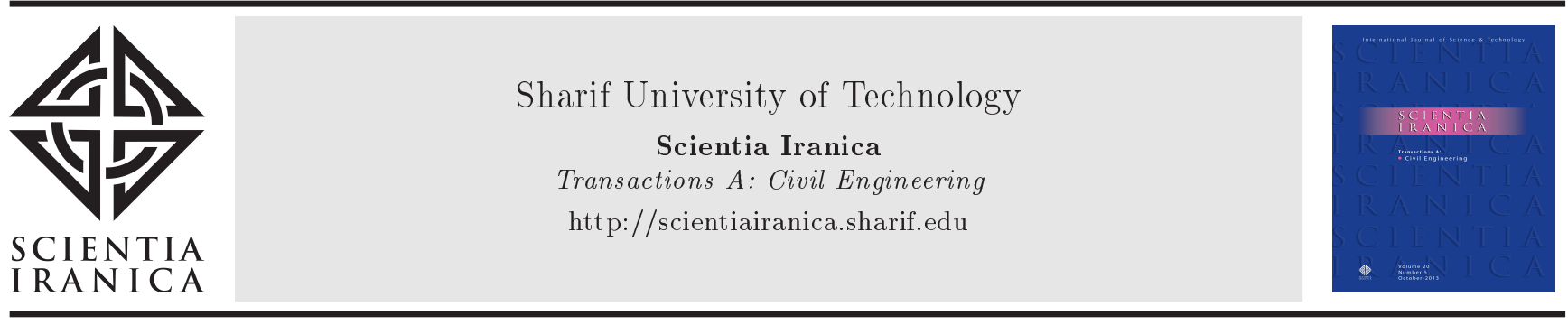

\title{
Investigation of wind-induced response of fluid-solid coupling system for high bent-type aqueduct
}

\author{
H. Zhang*, L. Liu, X. He, and A. Ji \\ College of Civil and Transportation Engineering, Hohai University, Nanjing, 210098, P.R. China.
}

Received 29 June 2015; received in revised form 28 June 2016; accepted 6 May 2017

\author{
KEYWORDS \\ High bent-type \\ aqueduct; \\ Fluctuating wind; \\ Wind-induced \\ response; \\ Water-aqueduct \\ coupling system; \\ ALE method.
}

\begin{abstract}
In this paper, the coupling responses of water and high bent-type aqueduct under wind loads were studied by the Arbitrary Lagrangian-Eulerian (ALE) method. The natural vibration characteristics and transversal displacement, stress, overturning force, overturning moment, and hydrodynamic pressure of water-aqueduct coupling system were comparatively analyzed under different conditions of water-depth, cross-section shape of aqueduct tank, and support bearing. The research results show that the isolated support changes the dynamic characteristics and reduces wind-resistant performance of U-shape aqueduct. Therefore, the dynamic performance is better under the effect of the fluctuating wind; however, the stiffness for U-shape aqueduct is smaller than that for the rectangular aqueduct, with the same water fluxes.
\end{abstract}

(C) 2018 Sharif University of Technology. All rights reserved.

\section{Introduction}

In order to efficiently solve the problems, such as the unevenness of water resources in geographical distribution, and realize the sustainable development of the national economy, many large aqueducts have been widely built in South-to-North Water Transfer Project in China in recent years. There are 1,670 highway bridges, water gates, tunnels, and aqueducts, including 49 large aqueducts, which have been built in Southto-North Water Transfer Project [1]. Most aqueducts are actually located in the open area or valleys, the windward area of tank is large, and transversal rigidness of aqueduct, especially high bent-type aqueduct (shown in Figure 1), is not strong enough to resist the turbulent wind loads. Practically, several wind damage accidents occurred since 1980s in China [2]. There are no codes specialized in the design of wind resistance

*. Corresponding author. Tel.: +86 15261455275

E-mail address: zh750808wx@163.com (H. Zhang) of the aqueduct. The design of wind resistance of the aqueduct is made according to the codes of high-rise buildings and others while the wind-resistant ability of some aqueducts is not enough to resist the wind loads. The wind loads are usually considered as static loads in the research of aqueducts, but the fluctuating effects of the wind not only affect the fatigue life, but also bring about the resonance in some cases so as to increase the danger to aqueduct structures damage. Therefore, the research on wind-resistant design of the high bent-type aqueduct structures has been an important subject of research in many actual hydraulic projects.

The fluctuating effects of wind not only influence the fatigue life of aqueduct, but also might cause large amplitude sloshing of water and even result in structural resonance in some cases, which would increase the probability of structural damage. In recent years, the investigations on the dynamic properties of aqueduct have been focused on the dynamic characteristics and responses under earthquake; however, in comparison with the building and bridge, the wind-resistant performance of aqueduct structure has been poorly and inadequately studied. $\mathrm{Li}$ et al. obtained the wind 


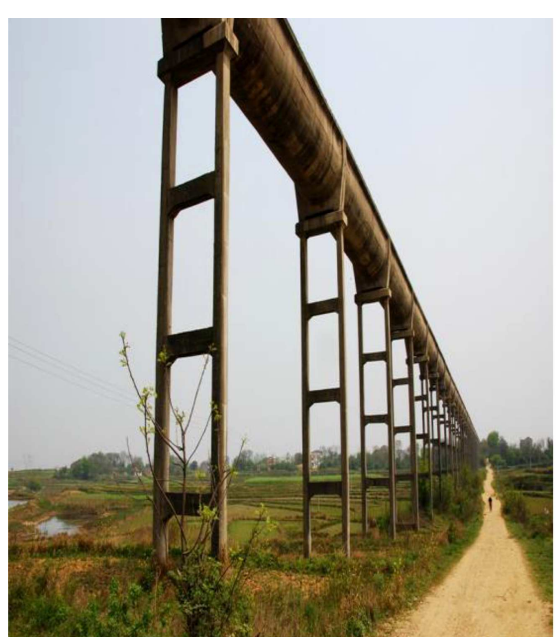

(a)

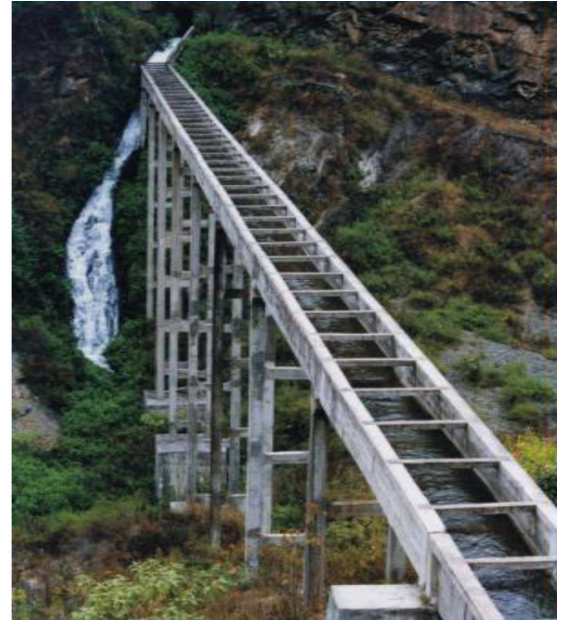

(b)

Figure 1. High bent-type aqueduct: (a) U-shaped aqueduct and (b) rectangular aqueduct.

load shape coefficient of U-shaped and rectangular aqueducts through the wind tunnel experiment [3,4]. The fluctuating wind can be treated as a steady Gauss stochastic process if the initial unsteady process of wind speed records is ignored. Therefore, the wind field can be simulated by the artificial simulation method [5-7]. The Auto-Regressive and Moving Average (ARMA) method is proposed in this study to simulate the fluctuating wind speed time series based on given power spectrum density of wind velocity for aqueduct structures.

The isolated bearings are widely used in the bridge structures in order to improve the dynamic properties and efficiently resist earthquake effects $[8,9]$. However, Zhang et al. [10] showed that the isolation remarkably increases the wind stress response and reduces wind-resistant performance of aqueduct. In this paper, the impact of isolated bearing on vibration mode and dynamic properties of aqueduct under wind loads is studied further. The large amplitude sloshing of water in the aqueduct tank under earthquake and strong wind effects could affect the structural stability and stress distribution of the aqueduct, especially for high bent-type aqueduct with isolated bearing. The stress distribution change of aqueduct would directly reduce the efficiency of pre-stressed steel bars, which would eventually cause cracks of aqueduct structure. Therefore, the coupling effects of water and aqueduct cannot be neglected while performing the dynamic analysis [11,12]. There are mainly two kinds of method for studying the water sloshing model and water-aqueduct interaction in current researches [1117]. The linear methods ignore the water sloshing effect, thus yielding inaccurate calculation results such as the additional mass method and Housner model method $[15,16]$, which regard water as an added mass or spring of the structure. Nonlinear methods could con- sider the influence of the fluid nonlinear sloshing on the structure, which mainly consist of boundary element method [14], Lagrange finite-element method [11], and Arbitrary Lagrangian-Eulerian (ALE) finite-element method [16,17]. Water is considered as an added mass of the structure through lens of the additional mass method which ignores the effects of water sloshing, thus yielding inaccurate calculation results. Housner proposed the Housnerian model of spring mass model, yet with low calculation accuracy of the connection of spring oscillator and the aqueduct structure. Boundary element was used to analyze water sloshing height and distribution of velocity potential; however, the effect of the aqueduct on the water is not considered. ALE method can solve the compatibility of the fluidstructure coupling interface under the condition of large amplitude water sloshing $[17,18]$.

The cross-section forms of aqueduct tank are mainly U-shaped, rectangular, trapezoidal, ovalshaped, tube-shaped, etc. in which U-shaped and rectangular aqueducts are widely used in practical engineering. $\mathrm{Li}$ et al. [3,4] showed that the wind load shape coefficients of U-shaped aqueduct are different from those of rectangular aqueduct because U-shaped aqueduct has no large sharp angle and its surface is smoother so that it is hard to lead to the wind flow separation, compared with the rectangular aqueduct. There are differences in wind load shape coefficients, lateral stiffnesses, hydrodynamic pressures, and stress distributions for aqueducts with various cross-section shapes; therefore, it is necessary to perform comparative investigations on the dynamic properties of aqueduct with different cross-section shapes under wind loads.

This paper is organized as follows. Section 1 introduces the literature review and research purpose. Section 2 proposes the fundamental equations of the fluid- 
solid coupling system. Section 3 presents the threedimensional (3D) finite-element model of the aqueduct and stochastic wind field simulation. Section 4 gives the analysis of numerical simulation. The last part, Section 5, offers the discussions and conclusions.

\section{Fundamental equations of fluid-solid coupling system}

\subsection{Dynamic equations for the structure}

Since the interaction effects of the fluid-structure interface in the coupling system should be included in the dynamic equation, the matrix form of dynamic equation which is derived from the weak form of Galerkin dynamic equation for the aqueduct structure subjected to the fluctuating wind loads can be expressed as follows $[19,20]$ :

$$
\mathbf{M} \ddot{\mathbf{u}}+\mathbf{C} \dot{\mathbf{u}}+\mathbf{K u}=\mathbf{P}_{W}(t)+\mathbf{P}_{L}(t),
$$

where $\mathbf{M}, \mathbf{C}$, and $\mathbf{K}$ are the mass damping and stiffness matrices, respectively. $\mathbf{u}, \dot{\mathbf{u}}$, and $\ddot{\mathbf{u}}$ are the relative displacement, velocity, and acceleration vectors at generic time $t$, respectively. $\mathbf{P}_{W}(t)$ is the external fluctuating wind load vector. $\mathbf{P}_{L}(t)$ is the fluid force on the structure.

\subsection{ALE description of the fluid-solid coupling equations}

Considering the ALE description, the mesh is generated in a reference coordinate system which is irrelevant to the structure and fluid movement. The mesh node denotes the reference node, which can move arbitrarily in space. To solve the compatibility of the fluid structure interface, the physical quantities in the fluid and structure domain can be described and mapped in the reference coordinate system by Jacobian determinant. The Navier-Stokes equations of the fluid in the ALE description can be written as follows [21-23]:

$$
\begin{aligned}
& \nabla \cdot \dot{\mathbf{u}}=0, \\
& \rho \ddot{\mathbf{u}}+\rho \dot{\mathbf{u}} \cdot \nabla \dot{\mathbf{u}}-\nabla \cdot \boldsymbol{\tau}=\mathbf{f}-\nabla \mathbf{P},
\end{aligned}
$$

where $\mathbf{u}$ is the displacement, $\dot{\mathbf{u}}$ and $\ddot{\mathbf{u}}$ are the first- and second-order differential invariants of $\mathbf{u}$ following time. $\mathbf{P}$ and $\mathbf{f}$ are the hydraulic pressure and body force, respectively; $\rho$ and $\tau$ are the fluid density and viscous stress tensor.

Under wind loads, movement of the aqueduct on the coupling interface leads to the sloshing of water, and the dynamic water pressure acts on the aqueduct wall on the interface which changes the distribution of deformation and stress of the aqueduct. The fluid and structure on the coupling interface satisfy the conditions of displacements continuity and equilibrium of forces:

$$
\text { Displacements continuity: } \quad \boldsymbol{\mu}_{f}=\boldsymbol{\mu}_{s},
$$

Equilibrium of forces: $\quad \boldsymbol{\sigma}_{f} \cdot \mathbf{n}_{f}-\boldsymbol{\sigma}_{s} \cdot \mathbf{n}_{s}=0$,

where $\boldsymbol{\mu}_{f}$ and $\boldsymbol{\mu}_{s}$ are the fluid displacement and structure displacement on the coupling interface, respectively; $\boldsymbol{\sigma}_{f}$ and $\boldsymbol{\sigma}_{s}$ are the fluid stress and structural stress on the interface, respectively; $\mathbf{n}_{f}$ and $\mathbf{u}_{s}$ are the unit outward normal vectors of the fluid and structure on the interface, respectively.

The normal velocity of the surface is identical to the normal velocity of the fluid on the free surface [24]:

$$
[\mathbf{v}(\xi, t)-\dot{\mathbf{x}}(\xi, t)] . \mathbf{n}=0 \quad \forall x \in \partial \Omega_{\text {free }},
$$

where $\xi$ is a point on the free surface, $t$ is the time, $\mathbf{v}(\xi, t)$ and $\dot{\mathbf{x}}(\xi, t)$ are the velocity of fluid and that of free surface, respectively, $\mathbf{n}$ is the unit normal vector, and $\Omega_{\text {free }}$ is the free surface.

\section{Three-dimensional model of high bent-type aqueduct under fluctuating wind loads}

In order to fully grasp the impact of the isolated support on the wind-induced dynamic performance of the water-aqueduct coupling system, a three-dimensional finite-element model of aqueduct structure is introduced in this paper. The fluctuating wind can be treated as a steady Gauss stochastic process if the initial unsteady process of wind speed records is ignored; therefore, the ARMA method is proposed to simulate the fluctuating wind speed time series in the previous study [10]. The simulated wind loads by ARMA method are added onto the calculation model of structure and 3D finite-element model of U-shaped and rectangular aqueducts under wind loads.

\subsection{Simulation of fluctuating wind velocity}

The ARMA model can simulate the stochastic wind speed time history, which has spatial and temporal correlations. The general linear process can be expressed by the difference equation as follows $[3,25]$ :

$$
X_{t}+\sum_{i=1}^{n} a_{i} X_{t-i}=\sum_{i=0}^{m} b_{i} \varepsilon_{t-i}
$$

where $X_{t}$ is the stationary random time series with zero mean, $\varepsilon_{t}$ is the pure random process, also called the white noise process, and $a_{i}$ and $b_{i}$ are the coefficients.

Herein, $X_{t}$ is the $m$ th order moving average process which is the $n$th order autoregressive, denoted by $\operatorname{ARMA}(n, m)$. Moreover, $a_{i}$ is the autoregressive coefficient, $b_{i}$ is the moving average coefficient, $n$ is the autoregressive order, and $m$ is the moving average order.

ARMA models are used specifically to simulate the fluctuating wind speed time series as follows:

$$
U_{t}+\sum_{i=0}^{p} A_{i} U(t-i \Delta t)=\sum_{j=0}^{q} B_{j} X(t-j \Delta t),
$$




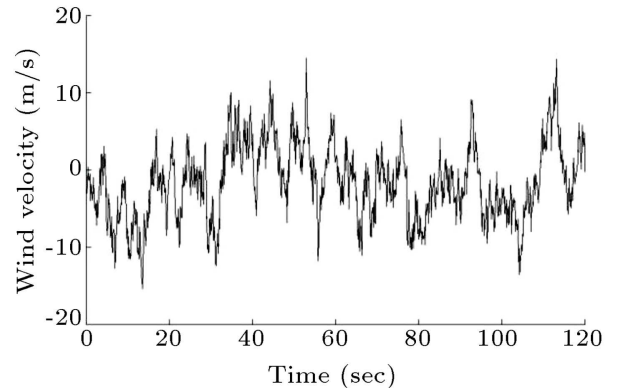

(a)

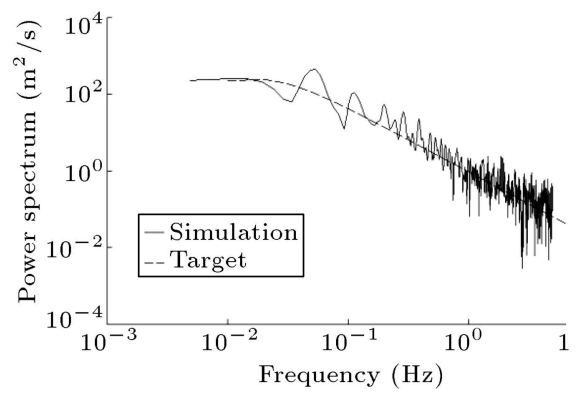

(b)

Figure 2. Simulation of fluctuating wind on aqueduct: (a) Time history of fluctuating wind velocity at 24 m, and (b) comparison of the power spectra between the simulation result and the target.

when $b_{0}=1$, the common expression used in the projects is obtained as follows:

$$
X_{t}+\sum_{i=1}^{n} a_{i} X_{t-i}=\varepsilon_{t}+\sum_{i=1}^{m} b_{i} \varepsilon_{t-i}
$$

when time shift operator $B: B_{i} X_{i}=X_{i-1}$ is introduced, Eq. (8) can be written as follows:

$$
\Phi(B) X_{t}=\Theta(B) \varepsilon_{t},
$$

where:

$$
\begin{aligned}
& \Phi(B)=1+a_{1} B+a_{2} B^{2}+\ldots .+a_{n} B^{n}, \\
& \Theta(B)=1+b_{1} B+b_{2} B^{2}+\ldots .+b_{m} B^{m} .
\end{aligned}
$$

The stationary and reversible conditions of ARMA models are determined by the autoregressive coefficient and the moving average coefficient, respectively, and can be judged whether the roots of $\Phi(B)=0$ and $\Theta(B)=0$ are all out of the unit circle in plane B.

The local basic wind pressure is $0.35 \mathrm{kN} / \mathrm{m}^{2}$. The fluctuating wind speed time series at different heights of the aqueduct structure is simulated using the Auto-Regressive Moving Average (ARMA) model. The Davenport power spectrum is employed as the target spectrum. In the analysis, duration $T$ is $120 \mathrm{~s}$, and time step is $\Delta t=0.1 \mathrm{~s}$. Seven fluctuating wind speed time series at different heights of aqueduct structure $(3.8 \mathrm{~m}, 9.5 \mathrm{~m}, 14.5 \mathrm{~m}, 20.0 \mathrm{~m}, 24.0 \mathrm{~m}$, $26.1 \mathrm{~m}$, and $29.7 \mathrm{~m}$ above the ground) are obtained by MATLAB software. Figure 2(a) shows the time history of fluctuating wind velocity at $24 \mathrm{~m}$ above the ground. Figure 2(b) compares the power spectra between the simulation result and the target. It can be seen that fit agreement between the two curves is good in Figure 2(b), indicating that the fluctuating wind is effectively simulated by ARMA model.

\subsection{D finite-element model of coupling system under wind loads}

The 3D finite-element models of fluid-solid coupling system for high bent-type U-shaped and rectangular aqueducts with plate rubber bearings are introduced as shown in Figures 3 and 4, respectively. Span $L$ of the aqueduct is $10 \mathrm{~m}$; height $H 1$ of $\mathrm{H}$-shaped supporting frame is $24 \mathrm{~m}$; width and height of the bar are $0.3 \mathrm{~m}$ and $0.4 \mathrm{~m}$, respectively. For U-shaped aqueduct, the radius of tank body is $2.2 \mathrm{~m}$; the height of U-shaped body is $5.6 \mathrm{~m}$; the thickness of tank wall is $0.5 \mathrm{~m}$. The plate rubber bearing is installed between the aqueduct body and supported frame. According to

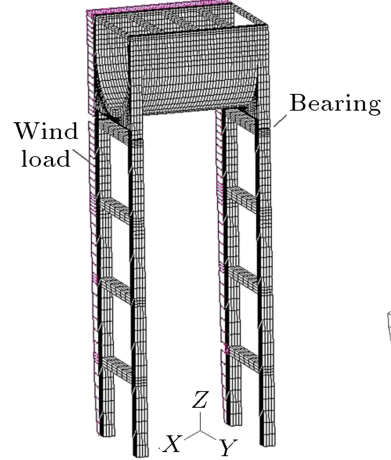

(a)

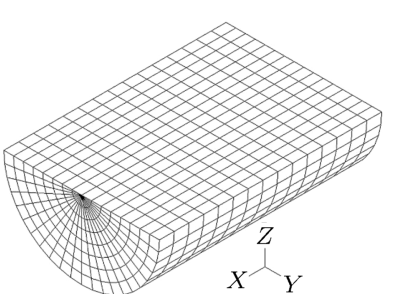

(b)
Figure 3. Diagram of finite-element model of U-shaped aqueduct: (a) Aqueduct structure and (b) water body.

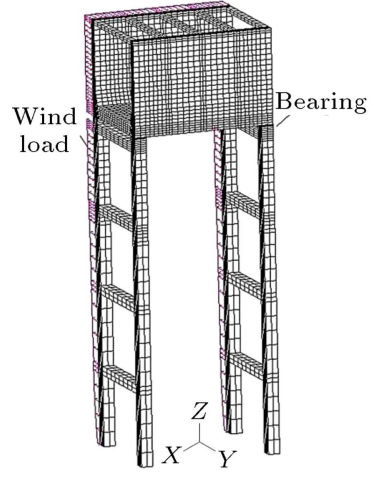

(a)

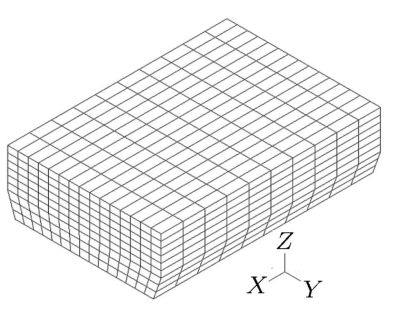

(b)
Figure 4. Diagram of finite-element model of rectangular aqueduct: (a) Aqueduct structure and (b) water body. 
the condition of the same dimension as cross-section U-shaped aqueduct body, for rectangular aqueduct, the width, height, and thickness of tank body are $7.0 \mathrm{~m}, 5.6 \mathrm{~m}$, and $0.5 \mathrm{~m}$, respectively. The aqueduct tank and supporting pier are built using C50 and C30 concretes, respectively. For the C50 concrete, Young's modulus, $E$, is $3.45 \times 10^{4} \mathrm{MPa}$ and Poisson's ratio, $\mu$, is 0.167 ; for the C30 concrete, Young's modulus, $E$, is $3.00 \times 10^{4} \mathrm{MPa}$ and Poisson's ratio, $\mu$, is 0.167 .

The time history of wind pressure at different heights of the aqueduct structure can be obtained by adding the simulated fluctuating wind speed and average wind speed (according to the relationship between wind speed and wind pressure). The aqueduct structure is modeled using 3D solid element, and the water in the tank is modeled by the $3 \mathrm{D}$ fluid element of CFD considering the water sloshing. The density of water is $1000 \mathrm{~kg} / \mathrm{m}^{3}$, and the viscous coefficient of water is $0.001 \mathrm{~N} . \mathrm{s} / \mathrm{m}^{2}$. The fluid-structure coupling boundary condition is applied onto the interface of the aqueduct and water, the water surface is modeled by boundary condition of free liquid surface, and the cross-section of the inlet and outlet water is modeled by slipping wall boundary condition. The bottom of the framed supports and displacements in the $X$-direction of the tank are fixed. In addition, half of the structure and water masses of the adjacent spans are added to the top of the supported frame in order to consider the influence of the adjacent spans of the aqueduct. For aqueducts with different cross-section shapes, six working conditions of water depth are chosen to analyze wind-induced responses of aqueduct according to the same flux principle. The working conditions of water depths of U-shaped and rectangular aqueducts are shown in Table 1 . The plate rubber bearing is made of the superimposition and vulcanizing bonding of thin rubber plate and thin steel plate as shown in Figure 5(a). There are 5-layer steel plate and 4-layer rubber plate. The thicknesses of single steel plate and rubber plate are $5 \mathrm{~mm}$ and $15 \mathrm{~mm}$, respectively. The finite-element model of laminated rubber bearing is shown in Figure 5(b). The steel plate and rubber plate are modeled using 3D solid element considering the nonlinear contact between both plates. The constitutive relation of rubber is modeled by Mooney-Rivlin strain energy density function, which is the function of the invariant of strain tensor $[26,27]$ :

$$
W=\sum_{i+j-1}^{n} C_{i j}\left(I_{i}-3\right)^{i}\left(I_{j}-3\right)^{j},
$$

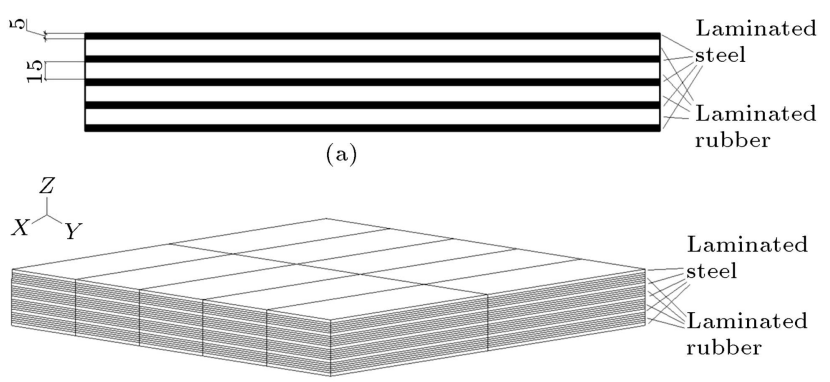

(b)

Figure 5. Diagram of laminated rubber bearing model: (a) Profile diagram ( $\mathrm{mm}$ ) and (b) finite-element model.

where $I_{i}$ is the invariant of Green strain, and $C_{i j}$ is the material parameter which is determined through the biaxial tensile test of rubber in this paper. The relation between Piola-Kirchhoff stress tensor, $\sigma_{i j}$, and Cauchy-Green strain tensor, $\gamma_{i j}$, is written as follows:

$$
\sigma_{i j}=\frac{\partial W}{\partial I_{1}}=\frac{\partial W}{\partial I_{1}} \frac{\partial I_{1}}{\partial \gamma_{i j}}+\frac{\partial W}{\partial I_{2}} \frac{\partial I_{2}}{\partial \gamma_{i j}}+\frac{\partial W}{\partial I_{3}} \frac{\partial I_{3}}{\partial \gamma_{i j}}
$$

The Trinomial formula of strain energy density function can be expressed as follows:

$$
\begin{aligned}
\mathbf{W}= & \mathbf{C}_{10}\left(\mathbf{I}_{1}-3\right)+\mathbf{C}_{01}\left(\mathbf{I}_{2}-3\right) \\
& +\mathbf{C}_{11}\left(\mathbf{I}_{1}-3\right)\left(\mathbf{I}_{2}-3\right)+\mathbf{C}_{20}\left(\mathbf{I}_{1}-3\right)^{2} \\
& +\mathbf{C}_{30}\left(\mathbf{I}_{2}-3\right)^{2},
\end{aligned}
$$

where $\mathbf{C}_{10}=206010 \mathrm{~Pa}, \mathbf{C}_{01}=1857.7 \mathrm{~Pa}, \mathbf{C}_{11}=$ $100.92 \mathrm{~Pa}, \mathbf{C}_{20}=4100.1 \mathrm{~Pa}$, and $\mathbf{C}_{30}=28070 \mathrm{~Pa}$. The steel plate is regarded as the elastic body, Young's modulus, $E$, is $2.06 \times 10^{11} \mathrm{~Pa}$, and Poisson's ratio, $\mu$, is 0.3 .

\section{Numerical analysis}

\subsection{Influence of the isolated bearing on wind-induced dynamic responses of $U$-shaped aqueduct}

4.1.1. Dynamic characteristics

The vibration modes of the aqueduct-water coupling system consist of the structure and fluid modes. The natural frequencies of the U-shaped aqueduct with rigid bearing and rubber isolated bearings are calculated, respectively, under different water depths, as shown in Table 2. The vibration period of the aqueduct with isolated bearing is 1.65 times larger than that of the aqueduct with rigid bearing under no water, showing that the rubber isolated bearing reduces structural

Table 1. Working conditions of water depth of U-shaped and rectangular aqueducts.

\begin{tabular}{ccccccc}
\hline Working condition & No. 1 & No. 2 & No. 3 & No. 4 & No. 5 & No. 6 \\
\hline U-shaped & Empty & $2.59 \mathrm{~m}$ & $3.5 \mathrm{~m}$ & $4.0 \mathrm{~m}$ & $4.5 \mathrm{~m}$ & $5.0 \mathrm{~m}$ \\
Rectangular & Empty & $1.939 \mathrm{~m}$ & $2.748 \mathrm{~m}$ & $3.248 \mathrm{~m}$ & $3.748 \mathrm{~m}$ & $4.248 \mathrm{~m}$ \\
\hline
\end{tabular}


Table 2. The natural vibration frequency of aqueduct structure $(\mathrm{Hz})$.

\begin{tabular}{|c|c|c|c|c|}
\hline \multirow[b]{2}{*}{ No. } & \multicolumn{2}{|c|}{ Rigid bearing } & \multicolumn{2}{|c|}{ Isolated bearing } \\
\hline & $\begin{array}{c}\text { No } \\
\text { water }\end{array}$ & $\begin{array}{c}\text { Water depth of } \\
3.5 \mathrm{~m} \\
\end{array}$ & $\begin{array}{c}\text { No } \\
\text { water }\end{array}$ & $\begin{array}{c}\text { Water depth of } \\
3.5 \mathrm{~m} \\
\end{array}$ \\
\hline 1 & 1.409 & 1.259 & 0.854 & 0.841 \\
\hline 2 & 4.710 & 4.690 & 2.210 & 2.195 \\
\hline 3 & 6.963 & 6.951 & 3.561 & 3.543 \\
\hline 4 & 7.216 & 7.119 & 5.685 & 5.656 \\
\hline 5 & 12.600 & 12.512 & 9.898 & 9.871 \\
\hline
\end{tabular}

stiffness and lengthens structural vibration. The water of tank reduces the natural vibration frequency, but the decline of frequency is low. Considering the similarity between dry and wet modes, we show only the first five dry vibration modes of the aqueduct model with rigid bearing and the rubber isolated bearing under no water condition, as shown in Figure 6. It can be observed in Figure 6 that the first vibration mode of aqueduct is the lateral mode, and the deflection of the frame support is large in every vibration mode. Since the lateral stiffness of the aqueduct and the stiffness of the frame support are small, the aqueduct could collapse in the transverse direction. Historic aqueducts have been destroyed when subjected to earthquake and wind loads. Furthermore, from the first three modes of the aqueduct with isolated support, the deformations of both the aqueduct body and supporting frame are small, while the deflection of the isolated support is large. Therefore, the application of isolation technol- ogy can significantly reduce vibration responses of an aqueduct structure.

\subsubsection{Dynamic displacement analysis}

The displacements under wind load are calculated and analyzed respectively under the following four working conditions: water depths of $3.5 \mathrm{~m}, 4.5 \mathrm{~m}, 5 \mathrm{~m}$, and no water in the aqueduct. Figure 7 shows the time history of transversal displacements at the top of the mid-span of the aqueduct with rigid and isolated bearings of no water in the aqueduct and the water depth of $4.5 \mathrm{~m}$ under wind loads. According to the displacement curves, the displacement response's rules of the aqueduct with rigid and isolated bearings are basically in accordance under the same water depth conditions. Transversal rigidity of the aqueduct decreased due to the setting of isolated bearings. The transversal displacements of the isolated aqueduct under the wind effect are larger than those of the aqueduct with rigid bearings.

Table 3 shows the maximum transversal displacements at the top of the U-shaped aqueduct with the following five working conditions: no water in the aqueduct, water depths of $2.59 \mathrm{~m}, 3.5 \mathrm{~m}, 4.0 \mathrm{~m}$, and $5.0 \mathrm{~m}$. Based on Table 3, transversal displacements of the aqueduct with water are larger than those without water. Besides, with the increase of the depth of water in aqueduct, the transversal displacements of the aqueduct have a less increment. Furthermore, the transversal displacements at mid span of the top of the aqueduct are larger than those at bearing of the top of the aqueduct with the same water depth condition,

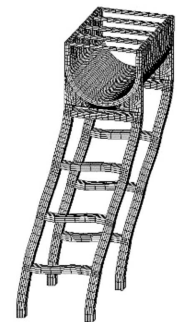

Mode 1

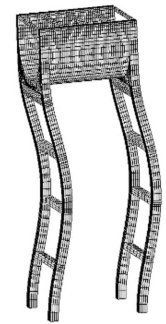

Mode 2

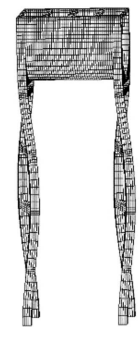

Mode 3

(a)

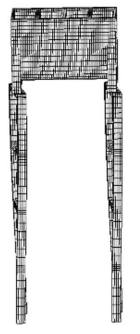

Mode 3

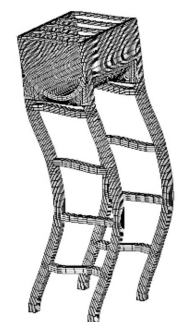

Mode 4

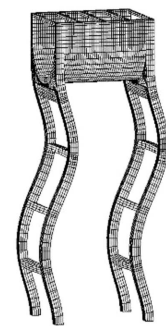

Mode 5

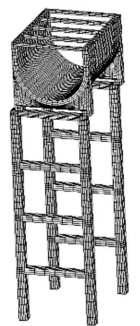

Mode 1

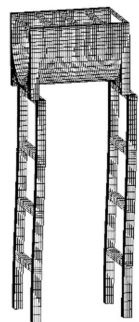

Mode 2

(b)

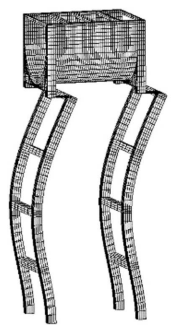

Mode 4

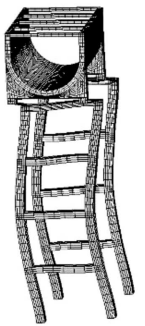

Mode 5

Figure 6. The vibration mode of the U-shaped aqueduct: (a) Rigid bearing and (b) isolated bearing. 

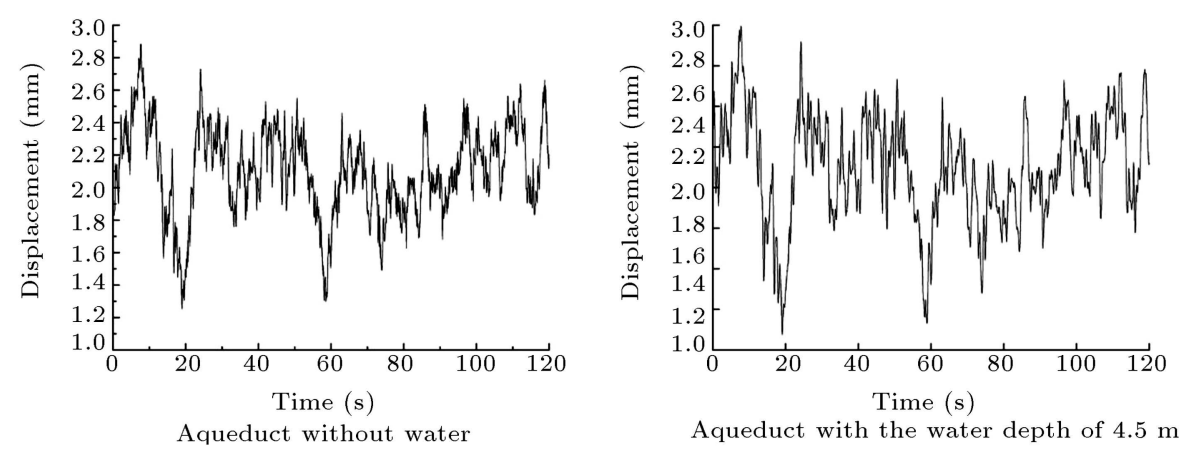

(a)
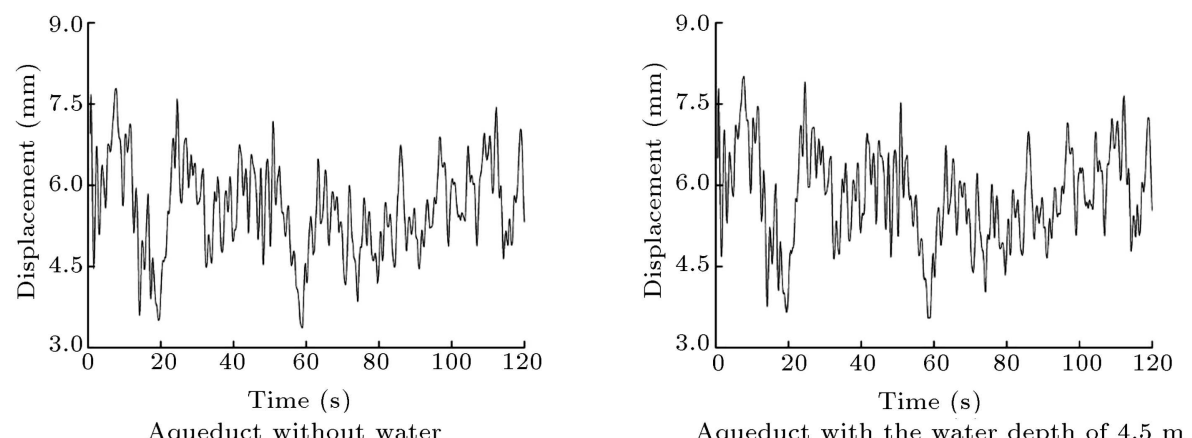

(b)

Figure 7. Transversal displacements at the top of the mid-span of the U-shaped aqueduct: (a) Rigid bearing, and (b) isolated bearing.

Table 3. Maximum transversal displacement of the U-shaped aqueduct with different conditions (mm).

\begin{tabular}{|c|c|c|c|c|c|c|c|}
\hline \multirow{2}{*}{\multicolumn{2}{|c|}{ Location }} & \multicolumn{6}{|c|}{ Water depth } \\
\hline & & No water & $2.59 \mathrm{~m}$ & $3.5 \mathrm{~m}$ & $4.0 \mathrm{~m}$ & $4.5 \mathrm{~m}$ & $5.0 \mathrm{~m}$ \\
\hline \multirow{2}{*}{ Rigid bearing } & Top of aqueduct body at mid-span & 2.883 & 2.976 & 2.983 & 2.986 & 2.991 & 2.995 \\
\hline & Top of aqueduct body at bearing & 2.762 & 2.763 & 2.764 & 2.768 & 2.778 & 2.816 \\
\hline \multirow{2}{*}{ Isolated bearing } & Top of aqueduct body at mid-span & 7.781 & 7.849 & 7.939 & 7.969 & 8.016 & 8.090 \\
\hline & Top of aqueduct body at bearing & 7.708 & 7.716 & 7.751 & 7.832 & 7.959 & 8.032 \\
\hline
\end{tabular}

showing that the amplitude at the body of the aqueduct is larger than that at the bearing of the aqueduct.

The maximum displacements of the aqueduct between rigid and isolated bearings contrast, and the latter is larger than the former under the same water depth conditions. The displacement of the aqueduct with isolated bearings is about 2.8 times of the aqueduct with rigid bearings under the high water-level condition. Hence, the application of isolation technology reduces the wind-resistant stiffness of the aqueducts and increases the wind displacement response, to which should be paid more attention in the wind-resistant design of the aqueduct structure.

\subsubsection{Dynamic stress analysis}

The dynamic stresses of the aqueduct with rigid and isolated bearings are respectively calculated and analyzed under the following four working conditions: water depths of $3.5 \mathrm{~m}, 4.0 \mathrm{~m}, 4.5 \mathrm{~m}$, and $5.0 \mathrm{~m}$. Figure 8 shows the major principal stress of middle cross-section of the aqueduct with rigid and isolated bearings, with water depths of $3.5 \mathrm{~m}$ and $4.5 \mathrm{~m}$. From Figure 8 , we find that the distribution patterns of the main stresses of the aqueduct with rigid bearings and isolated bearings are similar. However, the latter is larger than the former at the same location.

The maximum principal stresses on the U-shaped aqueduct with the water depths of $3.5 \mathrm{~m}, 4.0 \mathrm{~m}, 4.5 \mathrm{~m}$, and $5.0 \mathrm{~m}$ are, respectively, shown in Table 4 . It can be seen in Table 4 that as the depth of water in the aqueduct increases, the maximum principal stresses on the structure increase. The maximum principal stress on the inner wall of tank is smaller than that on the outer wall of tank. Besides, the principal stresses on the middle-cross section are slightly larger than those on the bearing section. The stresses on the aqueduct 


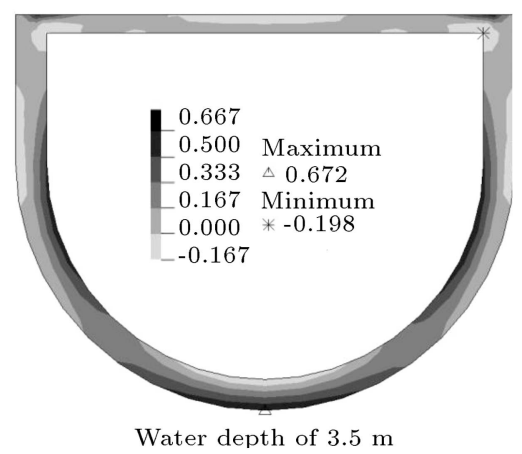

(a)

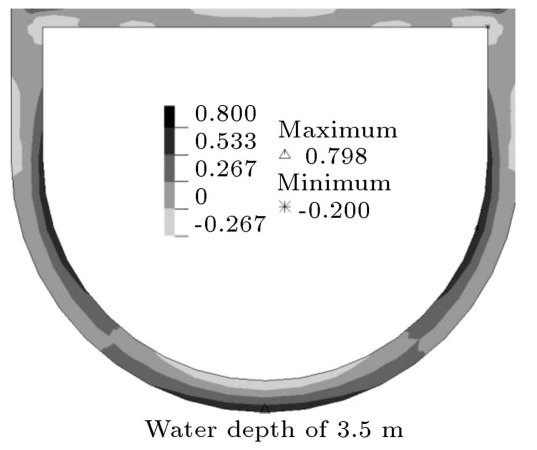

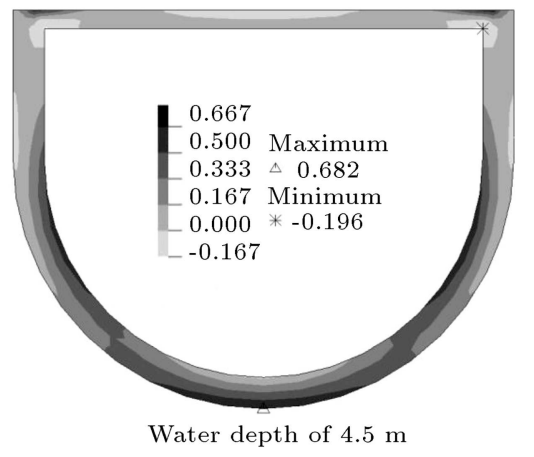

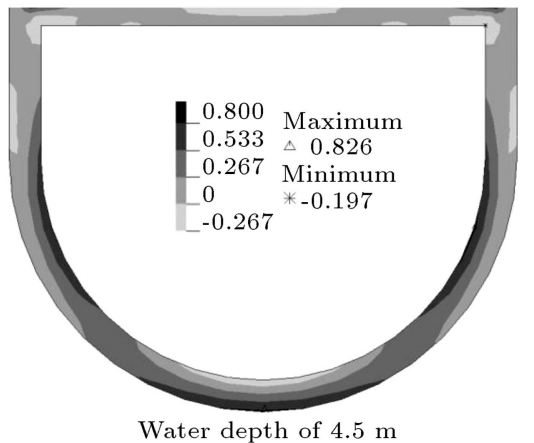

(b)

Figure 8. Major principal stress of middle cross-section of the U-shape aqueduct with water depths of $3.5 \mathrm{~m}$ and $4.5 \mathrm{~m}(\mathrm{MPa})$ : (a) Rigid bearing, and (b) isolated bearing.

Table 4. Maximum principal stress on the U-shaped aqueduct under different water-level conditions (MPa).

\begin{tabular}{|c|c|c|c|c|c|c|c|c|c|}
\hline \multirow[b]{2}{*}{ Location } & & \multicolumn{4}{|c|}{ Rigid bearing } & \multicolumn{4}{|c|}{ Isolated bearing } \\
\hline & & $3.5 \mathrm{~m}$ & $4.0 \mathrm{~m}$ & $4.5 \mathrm{~m}$ & $5.0 \mathrm{~m}$ & $3.5 \mathrm{~m}$ & $4.0 \mathrm{~m}$ & $4.5 \mathrm{~m}$ & $5.0 \mathrm{~m}$ \\
\hline \multirow{3}{*}{ Aqueduct body section at bearings } & Bar & 0.657 & 0.660 & 0.662 & 0.680 & 0.771 & 0.785 & 0.811 & 0.820 \\
\hline & Outer wall of tank & 0.663 & 0.673 & 0.677 & 0.683 & 0.795 & 0.800 & 0.818 & 0.831 \\
\hline & Inner wall of tank & 0.661 & 0.669 & 0.670 & 0.678 & 0.789 & 0.789 & 0.805 & 0.822 \\
\hline \multirow{3}{*}{ Aqueduct body section at mid-spans } & Bar & 0.668 & 0.670 & 0.679 & 0.681 & 0.771 & 0.762 & 0.815 & 0.806 \\
\hline & Outer wall of tank & 0.672 & 0.673 & 0.682 & 0.683 & 0.798 & 0.808 & 0.826 & 0.831 \\
\hline & Inner wall of tank & 0.669 & 0.670 & 0.677 & 0.682 & 0.788 & 0.800 & 0.819 & 0.825 \\
\hline \multirow{2}{*}{ Bents } & Column of bent & 0.425 & 0.513 & 0.540 & 0.584 & 0.503 & 0.554 & 0.618 & 0.622 \\
\hline & Beam of bent & 0.577 & 0.610 & 0.643 & 0.657 & 0.681 & 0.700 & 0.752 & 0.790 \\
\hline
\end{tabular}

with isolated bearings are larger than those with rigid bearings under the wind load. The stresses on the bar, tank and the framed support increase by $20.0 \%$, $21.7 \%$, and $18.4 \%$ with the application of isolation, respectively.

\subsubsection{Overturning force analysis}

The aqueduct would have a greater overturning force due to the fluctuating effect of wind speed and sloshing of the water in the tank under the wind load. Besides, the application of isolated bearings reduces the transversal displacement of the aqueduct. Moreover, the larger overturning force leads to the increase of the transversal displacement of the aqueduct, which may cause instability of the structure. Therefore, conducting research on overturning force of the aqueduct is necessary.

Overturning forces on the aqueduct under wind load are calculated under the following five working conditions: water depths of $2.59 \mathrm{~m}, 3.5 \mathrm{~m}, 4.0 \mathrm{~m}$, $4.5 \mathrm{~m}$, and $5.0 \mathrm{~m}$, respectively. The result shows that the overturning forces are fluctuating up and down near the average values under various water conditions. Table 5 shows the maximum overturning forces on 
the U-shaped aqueduct under various water conditions. The maximum overturning forces on the middle crosssection of the aqueduct with rigid and isolated bearings, respectively, reach $22.282 \mathrm{kN}$ and $30.030 \mathrm{kN}$ with the high water condition of $5.0 \mathrm{~m}$, which all exceed the overturning forces 2 times with the low water condition of $2.59 \mathrm{~m}$, indicating that the water depths of the tank have great impact on the overturning forces on the aqueduct. The aqueduct with isolated bearings has a maximum increase of overturning forces of $31.8 \%$ than the aqueduct with rigid bearings. Besides, the overturning forces on the aqueduct with rigid bearings change more greatly than those on the aqueduct with isolated bearings.

Sloshing water reacts in the tank under the wind load which produces overturning moment, and the overturning moments produced by the sloshing water increase with the increase of water depths. Table 6 shows the maximum overturning moments on the lower right corner of aqueduct under different working conditions. It can be seen from Table 6 that the overturning moments on the bearings of the aqueduct are close to those on the middle cross-section of the aqueduct, and their amplitude increase rates are all large corresponding to the increase of water depths. The maximum overturning moments on the U-shaped aqueduct with rigid and isolated bearings, respectively, reach $271.55 \mathrm{kN} . \mathrm{m}$ and $274.74 \mathrm{kN}$.m with the high water depth of $5.0 \mathrm{~m}$, showing that overturning moments on the aqueduct with isolated bearings increase while the amplitude increase is small. Therefore, considering the effect of the overturning moments on the structure, enough attention should be paid to the wind-resistant design of aqueduct structures.

\subsubsection{Hydrodynamic pressure analysis}

Time histories of hydrodynamic pressure on the lower right corner of the aqueduct with rigid and isolated bearings are calculated under various water level conditions. Changes in the time histories of hydrodynamic pressures on the middle cross-section are basically in accordance with that on the bearing cross-section. Table 7 shows the maximum hydrodynamic pressures on the tank wall of U-shaped aqueduct under differ-

Table 5. Maximum overturning forces on the U-shaped aqueduct under different water-level conditions $(\mathrm{kN})$.

\begin{tabular}{ccccccc}
\hline & & \multicolumn{4}{c}{ Water depth condition } \\
\cline { 3 - 6 } & Location & $\mathbf{2 . 5 9} \mathbf{~ m}$ & $\mathbf{3 . 5} \mathbf{~ m}$ & $\mathbf{4 . 0} \mathbf{~ m}$ & $\mathbf{4 . 5} \mathbf{~ m}$ & $\mathbf{5 . 0} \mathbf{~ m}$ \\
\hline \multirow{2}{*}{$\begin{array}{c}\text { Aqueduct with } \\
\text { rigid bearings }\end{array}$} & Lower right corner of middle cross-section & 10.630 & 14.980 & 17.411 & 19.847 & 22.282 \\
& Lower right corner of bearing cross-section & 5.315 & 7.491 & 8.706 & 09.925 & 11.143 \\
\multirow{2}{*}{$\begin{array}{c}\text { Aqueduct with } \\
\text { isolated bearings }\end{array}$} & Lower right corner of middle cross-section & 11.717 & 16.005 & 22.432 & 26.232 & 30.030 \\
\hline
\end{tabular}

Table 6. Maximum overturning moments of U-shaped aqueduct under different working conditions (kN.m).

\begin{tabular}{ccccccc}
\hline & & \multicolumn{5}{c}{ Water depth condition } \\
\cline { 3 - 7 } & Location & $\mathbf{2 . 5 9} \mathbf{~ m}$ & $\mathbf{3 . 5} \mathbf{~ m}$ & $\mathbf{4 . 0} \mathbf{~ m}$ & $\mathbf{4 . 5} \mathbf{~ m}$ & $\mathbf{5 . 0} \mathbf{~ m}$ \\
\hline $\begin{array}{c}\text { Aqueduct with } \\
\text { rigid bearings }\end{array}$ & Lower right corner of middle cross-section & 130.00 & 179.31 & 212.36 & 241.96 & 271.55 \\
& Lower right corner of bearing cross-section & 65.00 & 81.77 & 106.19 & 120.98 & 135.77 \\
\multirow{2}{*}{$\begin{array}{c}\text { Aqueduct with } \\
\text { isolated bearings }\end{array}$} & Lower right corner of middle cross-section & 130.10 & 179.44 & 212.49 & 242.11 & 274.74 \\
\hline
\end{tabular}

Table 7. Maximum hydrodynamic pressures on the tank wall of U-shaped aqueduct under different working conditions $(\mathrm{kPa})$.

\begin{tabular}{|c|c|c|c|c|c|c|}
\hline \multirow{2}{*}{\multicolumn{2}{|c|}{ Location }} & \multicolumn{5}{|c|}{ Water level condition } \\
\hline & & $2.59 \mathrm{~m}$ & $3.5 \mathrm{~m}$ & $4.0 \mathrm{~m}$ & $4.5 \mathrm{~m}$ & $5.0 \mathrm{~m}$ \\
\hline \multirow{2}{*}{$\begin{array}{l}\text { Aqueduct with } \\
\text { rigid bearing }\end{array}$} & Lower right corner of the middle cross-section & 23.201 & 31.419 & 36.091 & 40.991 & 45.890 \\
\hline & Lower right corner of the bearing cross-section & 23.201 & 31.393 & 36.091 & 39.165 & 45.891 \\
\hline \multirow{2}{*}{$\begin{array}{l}\text { Aqueduct with } \\
\text { isolated bearing }\end{array}$} & Lower right corner of the middle cross-section & 23.216 & 31.421 & 36.098 & 40.991 & 45.902 \\
\hline & Lower right corner of the bearing cross-section & 23.215 & 31.417 & 36.105 & 41.006 & 43.612 \\
\hline
\end{tabular}


ent working conditions. Under the water depths of $2.59 \mathrm{~m}, 3.5 \mathrm{~m}, 4.0 \mathrm{~m}, 4.5 \mathrm{~m}$, and $5.0 \mathrm{~m}$, the water depth increases by $35.1 \%, 14.3 \%, 12.5 \%$, and $11.1 \%$, respectively. The maximum hydrodynamic pressure on the middle cross-section of the aqueduct with rigid bearings increases by $35.4 \%, 14.9 \%, 13.6 \%$, and $12.0 \%$, respectively, and the maximum hydrodynamic pressure on the middle cross-section of the aqueduct with isolated bearings respectively increase by $35.3 \%, 14.9 \%$, $13.6 \%$, and $12.0 \%$, and the amplitude increase rates of water depths and hydrodynamic pressures are closer. Therefore, it is shown that water depth is a major factor in determining the size of the hydrodynamic pressures on the tank wall, while the application of isolated bearings has insignificant effect on the hydrodynamic pressures.

\subsection{Influence of the section form on wind-induced dynamic responses of aqueduct}

4.2.1. The natural vibration frequency analysis

Figure 9 shows the first ten frequencies of aqueduct with rigid and isolated bearings under the following conditions: different section aqueducts with no water, U-shaped aqueduct with water depth of $3.5 \mathrm{~m}$, and rectangular aqueduct with water depth of $2.748 \mathrm{~m}$.
It can be seen from the curves that there is inconsiderable difference in terms of the low-level vibration frequency between the rectangular and U-shaped aqueducts, while the high-level vibration frequency of the rectangular aqueduct is larger than that of the Ushaped aqueduct, showing that the integral rigidity of the rectangular aqueduct is larger than that of the Ushaped aqueduct.

\subsubsection{Dynamic displacement analysis}

There may be large differences between different section aqueducts of the wind-induced vibration properties of aqueduct-water coupling system. Thus, Ushaped and rectangular aqueducts are chosen and their wind-induced vibration responses are calculated and analyzed, respectively. Figure 10 shows the maximum transversal displacements on top of different section aqueducts. It can be seen from Figure 10 that the displacements of the rectangular aqueduct are larger than those of the U-shaped aqueduct under the same flow rate conditions. The larger the flow rate, the larger the displacements of the rectangular aqueduct than those of the U-shaped aqueduct when isolated bearings are set. The windward side of U-shaped aqueduct does not have a large sharp angle to cause the wind flow separation which leads to a large difference of

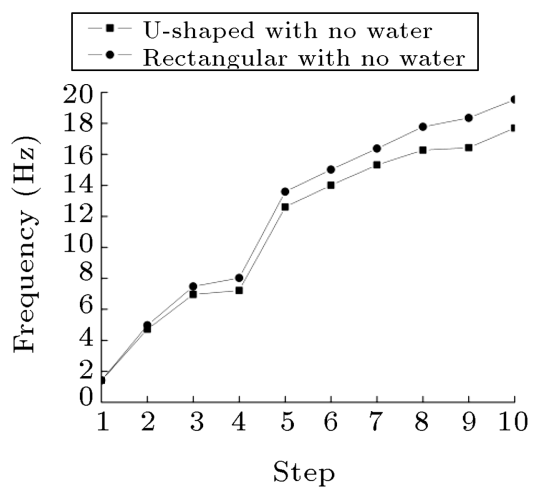

- - U-shaped with water depth of $3.5 \mathrm{~m}$ and
- - Rectangular with water depth of $2.748 \mathrm{~m}$

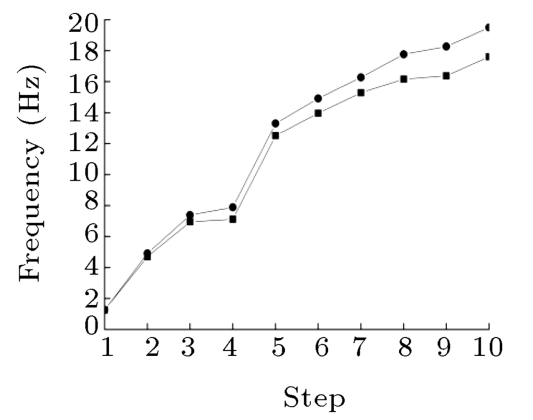

(a)

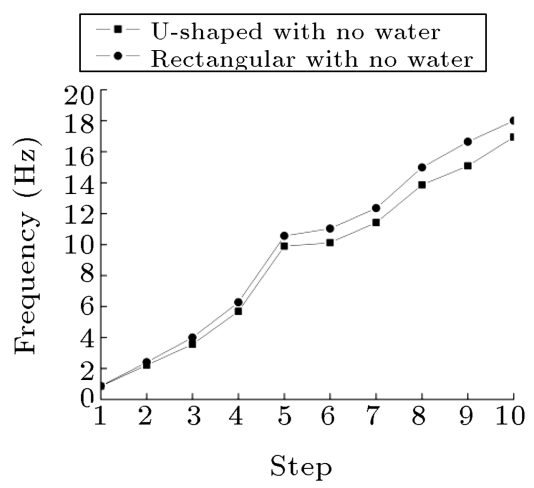

- U-shaped with water depth of $3.5 \mathrm{~m}$ and

- Rectangular with water depth of $2.748 \mathrm{~m}$

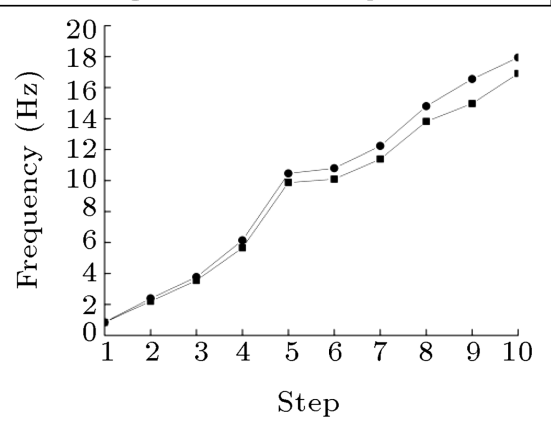

(b)

Figure 9. The first ten frequencies of aqueducts with different sections: (a) Rigid bearing, and (b) isolated bearing. 


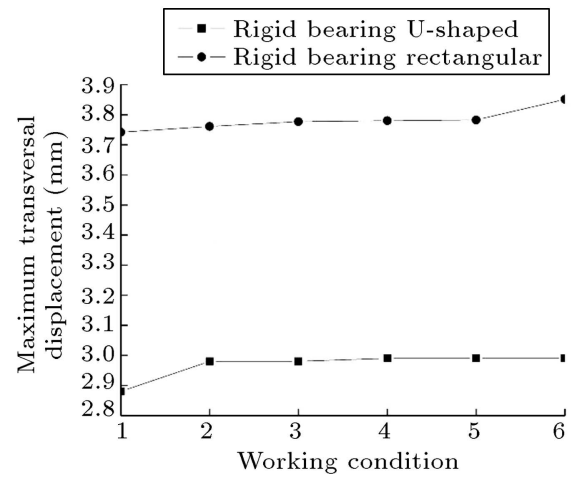

(a)

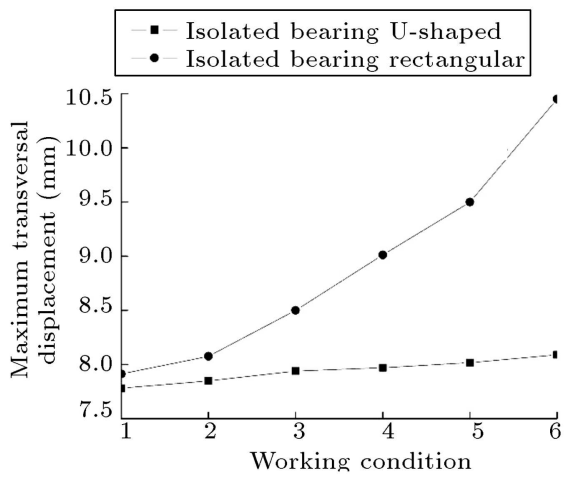

(b)

Figure 10. Maximum transversal displacements at the top of aqueducts with different sections: (a) Rigid bearing and (b) isolated bearing.

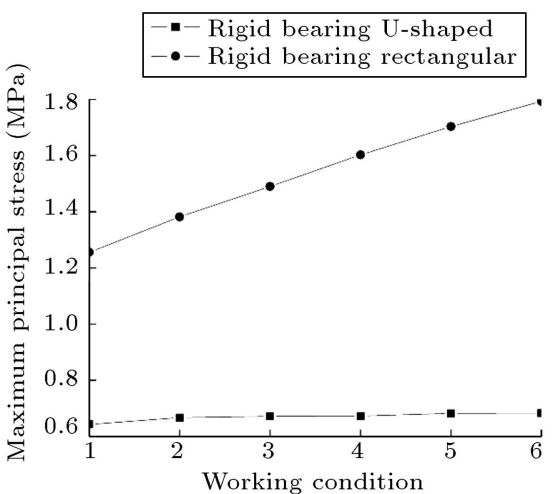

(a)

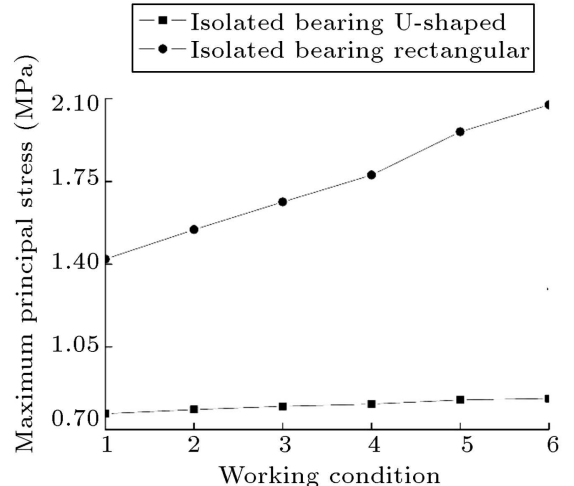

(b)

Figure 11. Maximum principal stresses on the aqueduct body with different sections: (a) Rigid bearing and (b) isolated bearing.

the displacement responses compared with that of the rectangular aqueduct.

\subsubsection{Dynamic stresses analysis}

Figure 11 shows the maximum principal stresses of the aqueduct under six various water depth conditions. The principal stresses of the U-shaped and rectangular aqueducts are all linear variations with the increase of water depth, and the principal stresses on the rectangular aqueduct increase more quickly than those on the U-shaped aqueduct do. The principal stresses on the rectangular aqueduct are larger than those on the U-shaped aqueduct are under the same water depth conditions. The maximum principal stress on the U-shaped aqueduct reaches $0.831 \mathrm{MPa}$, which is 0.4 times the amount reached on the rectangular aqueduct, i.e. 2.074 $\mathrm{MPa}$, showing that the U-shaped aqueduct is better than the rectangular aqueduct when stress conditions under the wind load are considered.

\subsubsection{Overturning forces and overturning moments analyses}

Figure 12 shows the curves of maximum overturning forces on the body of the U-shaped and rectangular aqueducts under five different water depth conditions. It can be seen from Figure 12 that the overturning forces on the U-shaped and rectangular aqueducts all increase with the increase of water depth; however, the overturning forces on the body of the rectangular aqueduct are larger than those of the U-shaped aqueduct are, under the same water depth. Under the high water-level conditions, the overturning forces on the rectangular aqueduct with rigid bearings increase faster than those on the U-shaped aqueduct with rigid bearings, as water depth increases.

Figure 13 shows the maximum overturning moment curves of the aqueduct body under six different water depth conditions to study the influence of aqueduct sections on the wind-induced response of overturning moments. The overturning moments on the U-shaped and rectangular aqueducts are all varying linearly with the increase of water depth. The overturning moment on the rectangular aqueduct is larger than that on the U-shaped aqueduct when water depths are the same. The aforementioned issues show that this section of the aqueduct has a large impact on the overturning stability characteristics of aqueduct structures under wind loads. 


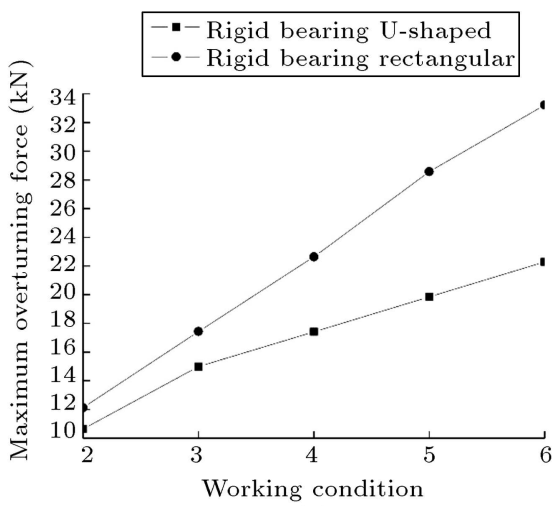

(a)

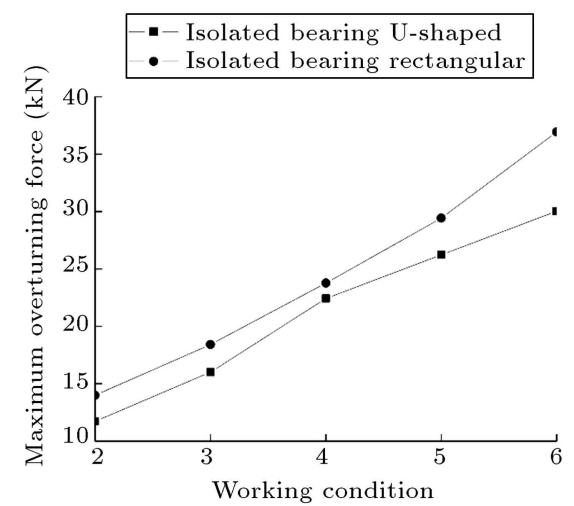

(b)

Figure 12. Maximum overturning forces on the aqueduct body with different sections: (a) Rigid bearing and (b) isolated bearing.

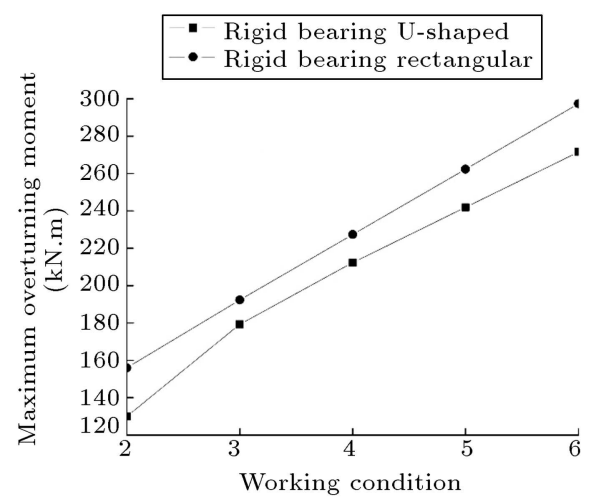

(a)

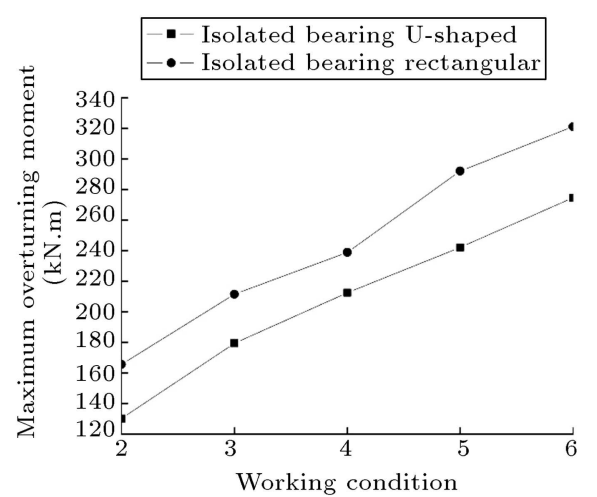

(b)

Figure 13. Maximum overturning moments on the aqueduct body with different sections: (a) Rigid bearing and (b) isolated bearing.

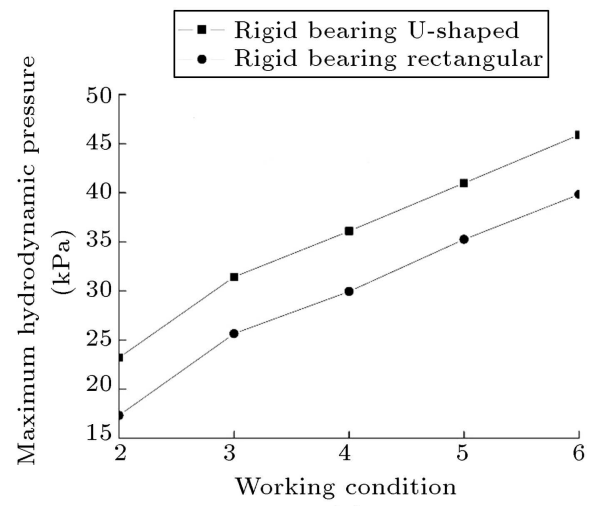

(a)

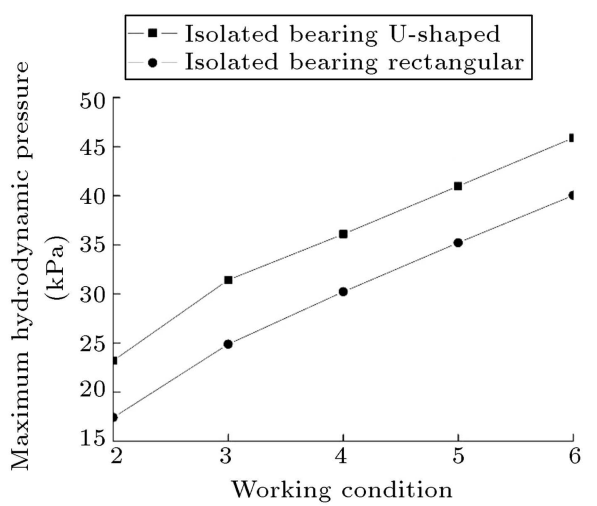

(b)

Figure 14. Maximum hydrodynamic pressures on the aqueduct body with different sections: (a) Rigid bearing and (b) isolated bearing.

\subsubsection{Hydrodynamic pressure analysis}

Figure 14 shows the curves of maximum hydrodynamic pressures on the U-shaped and rectangular aqueducts under different five water depth conditions. The overturning forces on the U-shaped and rectangular aqueducts all increase linearly as the water depth increases. However, the former is larger than the latter when the flow rates are the same. According to the test results on the existing literature and those calculated by this article, the hydrodynamic pressures on the tank mainly depend on the water depth of the tank and have little impact on the sloshing water. Because the water depth of the U-shaped aqueduct is larger than that of the rectangular one when flow rates are the 
same, the hydrodynamic pressure response of the Ushaped aqueduct is larger than that of the rectangular aqueduct.

\section{Conclusions}

In this paper, we investigated the wind-induced responses of high bent-type aqueducts with U-shaped and rectangular cross section. We obtained the following discussions and conclusions:

1. The transversal displacements of the aqueduct increase slowly under wind loads as the water depth increases. The displacement response of the U-shaped aqueduct is smaller than that of the rectangular one when the fluxes are the same. In addition, the displacement of the aqueduct with isolated bearings is about larger than that with rigid bearings under high water-level conditions. Thus, it is shown that the application of rigid bearings reduces the wind-resistant lateral stiffness of aqueduct structures and increases the displacement response of wind-induced vibration, such that wind deflectors or damping devices can be considered in wind-resistant designs of aqueduct structures to reduce the displacement response of the aqueduct;

2. The lower order vibration modes of the U-shaped and rectangular aqueducts are basically the same. Moreover, lower order natural frequencies of the rectangular aqueduct are closer to those of the Ushaped aqueduct when the fluxes are the same, while the higher order frequencies of the former are larger than those of the latter, showing that the section shape of aqueduct tank has more influence on the vibration characteristic of high orders for the aqueduct. Keeping these in mind, it is shown that the stiffness of the U-shaped aqueduct body is smaller than that of the rectangular one;

3. The principal stresses on the rectangular aqueduct are larger than those on the U-shaped aqueduct are, under the same water depth conditions. Besides, the larger stress on the inner wall of the tank appears on two sides of the wall because of the fluid-solid coupling interaction between the aqueduct and water. Therefore, dynamic interaction between the wall and water cannot be ignored in the aqueduct wind-resistant designs. The stresses on the aqueduct with isolated bearings are larger than those with rigid bearings are, under the wind load. To sum up, the U-shaped aqueduct has better properties derived from the calculation analysis of results of the displacement and stress responses under fluctuating wind loads;

4. The overturning forces and overturning moments of aqueduct structures change violently during the whole time history of wind load due to the influence of fluctuating speed and sloshing water. The overturning force and overturning moment both increase linearly with the increase of water depth. Moreover, the overturning forces and overturning moments on the rectangular aqueduct are larger than those on the U-shaped aqueduct are, when the fluxes are the same. Besides, the application of isolated bearings increases the overturning forces and overturning moments on aqueduct structures under the fluctuating wind loads. The maximum overturning moments on the U-shaped and rectangular aqueducts with isolated bearings are larger under high water-level conditions. Therefore, the influence of overturning moments on the stability of aqueduct structures should be paid enough attention in the aqueduct wind-resistance designs;

5. Water depth is the main factor in determining the size of the hydrodynamic pressures on the wall of the tank under wind loads, while the sloshing water and section of the aqueduct only have insignificant influence on the hydrodynamic pressures. The hydrodynamic pressures on the U-shaped aqueduct are larger than those on the rectangular aqueduct are, due to the fact that water depth in the U-shaped aqueduct is larger than that in the rectangular aqueduct when the fluxes are the same. The time history of hydrodynamic pressures shows that the dynamic interaction between the water and tank wall is a complicated nonlinear process. Hence, hydrodynamic pressures on tank walls cannot be ignored in calculating internal forces of aqueduct structures.

\section{References}

1. Wu, Y., Mo, H. and Yang, C. "Analyses of the dynamic characteristics of large-scale aqueduct-water coupling systems", Journal of South China University of Technology (Natural Science Edition), 32(9), pp. 7681(2004).

2. Li, Y. and Lou, M. "Computing method of windinduced vibration for tall-bent aqueduct", Journal of Tongji University (Natural Science), 30(2), pp. 139145 (2002).

3. Li, Z., Lou, M., Song, J. and Liang, S. " The wind tunnel test study on wind load shape coefficient of aqueduct body structure for U shape", Acta Aerodynamica Sinica, 20(2), pp. 233-245 (2002).

4. Li, Z., Lou, M., Song, J. and Pang, J. "Wind tunnel model test on shape coefficient of wind load for aqueduct", Journal of Hydraulic Engineering, 31(9), pp. 15-19 (2000).

5. Solari, G. and Spinelli, P. "Time-domain analysis of tall buildings response to wind action", 3rd Int. Conf. on Tall Buildings, pp. 278-284 (1984). 
6. Iwatani, Y. "Simulation of multidimensional wind fluctuations having any arbitrary power spectra and cross spectra", Journal of Wind Engineering, 11(1), pp. 5-18 (1982).

7. Di Paola, M. "Digital simulation of wind field velocity", Journal of Wind Engineering and Industrial Aerodynamics, 74(2), pp. 91-109 (1998).

8. Li, Y., Lou, M. and Pan, D. "Evaluation of vertical seismic response for a large-scale beam-supported aqueduct", Earthquake Engineering and Structural Dynamics, 32(1), pp. 1-14 (2002).

9. Davis, C. and O'Rourke, T. "Shakeout Scenario: Water system impacts from a Mw 7.8 San Andreas earthquake", Earthquake Spectra, 27(2), pp. 459-476 (2011).

10. Zhang, H., Liu, L., Dong, M. and Sun, H. "Analysis of wind-induced vibration of fluid-structure interaction system for isolated aqueduct bridge", Engineering Structures, 46(1), pp. 28-37 (2013).

11. Sawada, T. and Hisada, T. "Fluid-structure interaction analysis of a two-dimensional flag-in-wind problem by the ALE finite element method", JSME International Journal, Series A: Solid Mechanics and Material Engineering, 49(2), pp. 170-179 (2006).

12. Al-Amiri, A. and Khanafer, K. "Fluid-structure interaction analysis of mixed convection heat transfer in a lid-driven cavity with a flexible bottom wall", International Journal of Heat and Mass Transfer, 54(3), pp. 826-836 (2011).

13. Olson, L.G. and Bathe, K.-J. "Analysis of fluidstructure interactions. A direct symmetric coupled formulation based on the fluid velocity potential", Computers \& Structures, 21(1), pp. 21-32 (1985).

14. Nakayama, T. and Washizu, K. "The boundary element method applied to the analysis of twodimensional nonlinear sloshing problems", International Journal for Numerical Methods in Engineering, 17(11), pp. 1631-1646 (1981).

15. Housner, G.W. "The dynamic behavior of water tanks", Bulletin of the Seismological Society of America, 53(2), pp. 381-387 (1963).

16. Filipovic, N., Mijailovic, S., Tsuda, A. and Kojic, M. "An implicit algorithm within the arbitrary Lagrangian-Eulerian formulation for solving incompressible fluid flow with large boundary motions", Computer Methods in Applied Mechanics and Engineering, 195(44), pp. 6347-6361 (2006).

17. Bermudez, A., Duran, R. and Rodriguez, R. "Finite element solution of incompressible fluid-structure vibration problems", International Journal for Numerical Methods in Engineering, 40(8), pp. 1435-1448 (1997).

18. Kim, J.-M., Chang, S.-H. and Yun, C.-B. "Fluidstructure-soil interaction analysis of cylindrical liquid storage tanks subjected to horizontal earthquake loading", Structural Engineering and Mechanics, 13(6), pp. 615-638 (2002).
19. Shao, Y., Zhao, L. and Li, T. "Summary of dynamic calculation methods of fluid-solid coupled aqueduct", Yellow River, 27, pp. 55-56 (2005).

20. He, J., Liu, Y. and Sun, R. "Research on additional mass model's applicability in the seismic calculation of aqueduct", Journal of Xi'an University of Technology, 23(1), pp. 52-55 (2007).

21. Shin, S. and Lee, W.I. "Finite element analysis of incompressible viscous flow with moving free surface by selective volume of fluid method", International Journal of Heat and Fluid Flow, 21, pp. 197-206 (2000).

22. Wu, Y., Mo, H. and Yang, C. "ALE simulation of large sloshing of water in U-shaped aqueduct", Journal of South China University of Technology (Natural Science Edition), 31, pp. 90-93 (2003).

23. Peng, L. "Study on seismic-resistance and isolation of large-scale aqueduct", MS Thesis, Agricultural University of Hebei Province (2002).

24. $\mathrm{Xu}, \mathrm{W}$. "The calculation of the seismic response of aqueduct structure considering fluid-solid coupling", MS Thesis, Zhengzhou University (2004).

25. Wang, B., Liang, C., Chen, H. and Xu, J. "Nonlinear seismic response analysis of aqueduct constructed with lead rubber bearing for vibration isolation", Water Resources and Hydropower Engineering, 36(3), pp. 2830 (2005).

26. Zheng, M. and Wang, W. "Determination for mechanical constants of rubber Mooney-Rivlin model", China Rubber Industry, 50(8), pp. 462-465 (2003).

27. Pan, K.-M., Liu, B., Liu, Z.-Y. and Wang, X.-C. "Experimental analysis of the dynamic interaction between base and structure for base-isolated structure with rubber-bearing", Dongbei Daxue Xuebao/Journal of Northeastern University, 23(1), pp. 71-74 (2002).

\section{Biographies}

Hua Zhang is an Associate Professor (with tenure) in Hohai University. He received his $\mathrm{PhD}$ degree from Southeast University in China in 2002 and started an academic career as a faculty member at the Department of Civil Engineering, College of Civil and Transportation, Hohai University, China. He did a oneyear research at the Department of CEEM at Columbia University from August 2011 to August 2012. His research interests are mainly in the areas of structural dynamics, material dynamics, finite-element analysis, and long span space structures. Hua Zhang has written about fifty papers published in journals and proceedings and received dozens of research funding awards, such as National Science Foundation, Jiangsu Provision Science Foundation, National University Researcher Award, and so forth.

Liang Liu is an Engineer in the China Design Group 
Co. Ltd. He received his Master Degree from Hohai University in China in 2012. His research interests are mainly in the areas of structural dynamics and design of steel structures.

Xiangrui He is a master student at the Department of Civil Engineering, College of Civil and Transportation, Hohai University, China. His research interests are mainly in the areas of structural dynamics and finiteelement analysis.

Aili Ji is a master student at the Department of Civil Engineering, College of Civil and Transportation, Hohai University, China. His research interests are mainly in the areas of structural dynamics and finiteelement analysis. 